Article

\title{
Formulation and Safety Tests of a Wickerhamomyces anomalus-Based Product: Potential Use of Killer Toxins of a Mosquito Symbiotic Yeast to Limit Malaria Transmission
}

\author{
Alessia Cappelli ${ }^{1,+}+\mathbb{C}$, Consuelo Amantini ${ }^{1}$, Federica Maggi ${ }^{2,3}\left(\mathbb{D}\right.$, Guido Favia ${ }^{1,+}+\left(\mathbb{C}\right.$ and Irene Ricci ${ }^{1, *,+(\mathbb{D})}$ \\ 1 School of Biosciences and Veterinary Medicine, University of Camerino, 62032 Camerino, Italy; \\ alessia.cappelli@unicam.it (A.C.); consuelo.amantini@unicam.it (C.A.); guido.favia@unicam.it (G.F.) \\ 2 Department of Molecular Medicine, Sapienza University, 00185 Rome, Italy; federica.maggi@uniroma1.it \\ 3 Immunopathology Laboratory, School of Pharmacy, University of Camerino, 62032 Camerino, Italy \\ * Correspondence: irene.ricci@unicam.it \\ + CIRM Italian Malaria Network.
}

Citation: Cappelli, A.; Amantini, C.;

Maggi, F; Favia, G.; Ricci, I.

Formulation and Safety Tests of a Wickerhamomyces anomalus-Based Product: Potential Use of Killer Toxins of a Mosquito Symbiotic Yeast to Limit Malaria Transmission. Toxins 2021, 13, 676. https://doi.org/ $10.3390 /$ toxins 13100676

Received: 5 August 2021

Accepted: 18 September 2021

Published: 23 September 2021

Publisher's Note: MDPI stays neutral with regard to jurisdictional claims in published maps and institutional affiliations.

\begin{abstract}
Wickerhamomyces anomalus strain WaF17.12 is a yeast with an antiplasmodial property based on the production of a killer toxin. For its symbiotic association with Anopheles mosquitoes, it has been proposed for the control of malaria. In an applied view, we evaluated the yeast formulation by freeze-drying $\mathrm{WaF} 17.12$. The study was carried out by comparing yeast preparations stored at room temperature for different periods, demonstrating that lyophilization is a useful method to obtain a stable product in terms of cell growth reactivation and maintenance of the killer toxin antimicrobial activity. Moreover, cytotoxic assays on human cells were performed, showing no effects on the cell viability and the proinflammatory response. The post-formulation effectiveness of the killer toxin and the safety tests indicate that $W a \mathrm{~F} 17.12$ is a promising bioreagent able to impair the malaria parasite in vector mosquitoes.
\end{abstract}

Keywords: yeast killer toxin; Wickerhamomyces anomalus; symbiotic control; malaria; mosquitoes; vector-borne diseases; freeze drying; safety

Key Contribution: Freeze-drying protocols and cytotoxic effects of a strain of Wickerhamomyces anomalus, which produces an antiplasmodial killer toxin in malaria vector mosquitoes, were evaluated for the exploitation of an eco-friendly and safe yeast-based product against the transmission of vectorborne diseases.

\section{Introduction}

Wickerhamomyces anomalus (formerly Pichia anomala and Hansenula anomala) is a ubiquitous ascomycete yeast that is isolated from different sources, such as food, plants and insects [1]. In the last decade, this yeast has gained great attention for its applicability in food biopreservation and potential use in medicine, thanks to its ability to produce killer toxins (KTs) with a wide antimicrobial activity [1]. W. anomalus is deemed by the European Food Safety Authority (EFSA) to be a microbiological agent with a Qualified Presumption of Safety (QPS) status for use in the food industry [2]. Nevertheless, in-depth studies of the killer yeast effects on humans and the environment as well as tests of the maintenance of the KT-based antimicrobial properties in formulated products are necessary for its further biotechnological applications.

Interestingly, for its association as a mutualistic symbiont with insects that transmit diseases to humans and animals, such as mosquitoes and sandy flies, $W$. anomalus has been proposed also for the symbiotic control (SC) of vector-borne diseases (VBDs) [3,4]. Malaria is one of the most troubling VBDs, and the fight against vector mosquitoes is mainly based on insecticides. On the other hand, the insurgence of insecticide resistance limits the efficacy of this method, and thus, innovative strategies are urgently needed [5]. Taking 
into account also the toxicity and high costs of insecticides, the development of alternative strategies by the use of sustainable and eco-friendly products are under investigation [6]. A possible approach involves the dissemination in vector mosquitoes of inherited symbiotic yeasts that kill the malaria pathogen (Plasmodium) from an infected blood meal, by releasing KTs in the female midgut [3]. This strategy implicates the release of killer symbionts in malaria endemic areas to reduce the vector capability and block the transmission. Several studies showed that the strain of $W$. anomalus $W a F 17.12$, which localizes in the mosquito midgut and gonads and is vertically transmitted, impairs Plasmodium berghei in Anopheles stephensi (the major Asian malaria vector) through a KT-mediated effect that causes parasite membrane damage and death $[7,8]$.

The antiplasmodial effect of the KT secreted by WaF17.12 (WaF17.12-KT) and its biological relationship with the female mosquito are pivotal features for the SC of malaria. Nevertheless, the implementation of such a killer yeast-based product and the development of a commercialization pathway require additional investigations that include three main objectives: (i) assessment of effective delivery systems (e.g., dissemination in vector insects), (ii) optimization of low-cost industrial-scale culturing and storing (e.g., lyophilization), and (iii) evaluation of the toxicity. Concerning yeast dissemination, Cappelli and collaborators have demonstrated that the sugar diet in laboratory-reared mosquitoes can be supplemented with $W a F 17.12$, maintaining a KT-mediated antiplasmodial effect until the next generation [8]. In an applied view, the Saccharomycetes yeast could be dispersed on flowers, and the volatile substances produced by nectar fermentation would attract mosquitoes to their food sources $[9,10]$. Even though this strategy seems applicable, the question of how to turn yeast into a product remains open and requires demonstrations that it is cultivable on a large scale and formulable, i.e., resistant to transformation processes in terms of viability and biocontrol activity maintenance, as well as being absolutely safe. A lyophilized yeast preparation could be stored at room temperature (rt) and easily released in the environment at low cost.

In the present work, we performed formulation and safety tests, focusing on WaF17.12. The effect on the growth reactivation and the maintenance of the killer toxin activity after freeze-drying was evaluated, demonstrating that $W a \mathrm{~F} 17.12$ is a stress-tolerant strain that is transformable into a dried product, ready to use in the field. Concerning the safety, despite several killer strains of $W$. anomalus being used in the food industry [11], there are only a few studies demonstrating that mice orally treated with the yeast did not show collateral effects [12] and KTs did not harm murine hepatocytes and human erythrocytes in vitro $[8,13]$. Here, we estimated the effect of $W a F 17.12$ in terms of cell viability and the proinflammatory response on human keratinocyte cell lines, which represent the first barrier of the human body. The overall results obtained in this study represent a step forward in the commercialization of a KT producer strain of $W$. anomalus associated with vector mosquitoes as an innovative tool to prevent the spreading of VBDs.

\section{Results}

\subsection{Growth Reactivation and Killer Toxin Activity Maintenance of WaF17.12 after Lyophilization}

Lyophilization is one of the most successful and convenient methods to preserve high cell viability; thus, it is a common industrial technique to preserve microorganisms for a long time [14]. Nevertheless, the freeze-drying process could cause cell damage by ice crystals formation and an intracellular increase in the salt concentration and water leak, and thus, not all microbes are suitable for this treatment [15]. To investigate the possible use of freeze-drying of W. anomalus, the yeast growth rate and the KT activity of lyophilized $\mathrm{WaF} 17.12$ were analyzed after different periods of storage (rt) $(4,12,18,25,32$ and 60 days). Analysis of the yeast cultures was performed after $36 \mathrm{~h}$ of incubation at optimal conditions for stimulating the secretion of WaF17.12-KT [16] (Figure 1). 

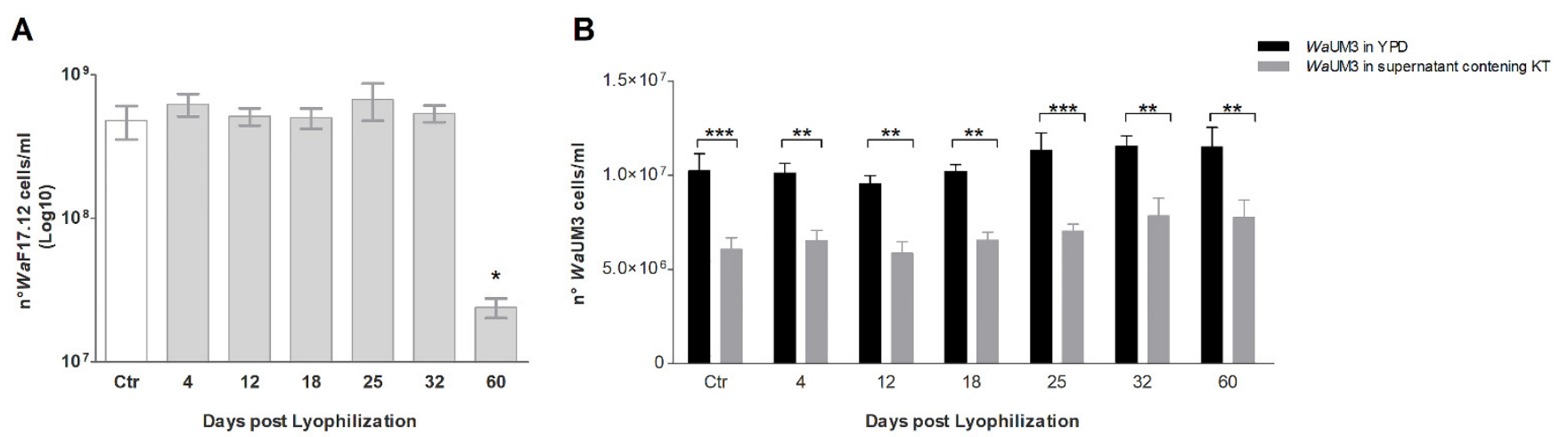

Figure 1. Analysis of the $W a F 17.12$ growth rate and KT activity against the sensible target WaUM3 after. (A) Growth rate of $W a F 17.12$ cultures was estimated at 4,12, 18, 25, 32 and 60 days of room temperature storage post freeze-drying, Ctr: non-lyophilized WaF17.12 culture. Cell counts were carried out using trypan blue assay. (B) Antimicrobial activity of supernatants containing WaF17.12-KT; Black bars: WaUM3 cultured overnight in YPD pH 4.5 (control); Grey bars: WaUM3 cultured in YPD pH 4.5 diluted with supernatants containing WaF17.12-KT (1:1). Cell counts were carried out using trypan blue assay. Both the experiments were performed twice, and the bars represented the mean \pm SEM for each group $\left({ }^{*} p<0.05 ;{ }^{* *} p<0.01 ;{ }^{* * *} p<0.001\right)$.

The cell counts were estimated using the trypan blue assay, which allowed to distinguish viable cells since staining occurs only in dead or damaged cells (Figure 1A). The growth rate showed no differences of lyophilized $W a F 17.12$ versus the fresh sample (Ctr) up to 32 days of storage, while a slowdown was detected after 60 days $(p<0.05)$. The results demonstrated constant yeast viability in terms of cell replication up to the fourth/fifth week post-lyophilization. Moreover, the trypan blue assay indicated that the yeast conserved cell membrane integrity in all the analyzed storage periods. This suggests that after two months of storage, the observed lower cell concentration is likely due to a slower rate of cell replication rather than a greater number of damaged or dead cells.

To evaluate the maintenance of the $W a F 17.12-K T$ activity after lyophilization, the antimicrobial effect of supernatants from the previously analyzed yeast cultures was tested against the sensible strain WaUM3 (Figure 1B). This analysis was performed because $\mathrm{WaF} 17.12-\mathrm{KT}$ is a soluble glycoprotein that is secreted under optimal growing conditions, and its presence in the supernatants was checked by Western blot, using a monoclonal antibody as previously described by Cappelli et al. [16]. WaF17.12-KT showed an unaltered antimicrobial activity against $\mathrm{WaUM} 3$, even in supernatants of cultures from yeast reactivated 60 days post-lyophilization likely due to the reaching of a secretion plateau at a cell concentration of $10^{7}-10^{8}$. The results suggested that, despite a slowdown in the yeast replacement by the longest period, the ability of $\mathrm{WaF} 17.12$ to maintain a killer phenotype remains unchanged.

\subsection{Effects of WaF17.12 on Viability of Human Keratinocytes (HaCaT)}

The effects of different concentrations of $W a \mathrm{~F} 17.12$ were tested on human keratinocytes since they represent the first defensive barrier of the body and are a useful target for cytotoxic studies [17]. The HaCaT cell line, a non-tumorigenic monoclonal spontaneously immortalized cell line that exhibits normal morphogenesis and expresses all the major surface markers and functional activities of isolated keratinocytes, was used as a model [18]. Cells were treated with 1000, 5000 and 10,000 yeast cells $/ \mathrm{mL}$, and the treatment effects on the viability of keratinocytes were evaluated at $24 \mathrm{~h}$ and $48 \mathrm{~h}$ (Figure 2). 
A

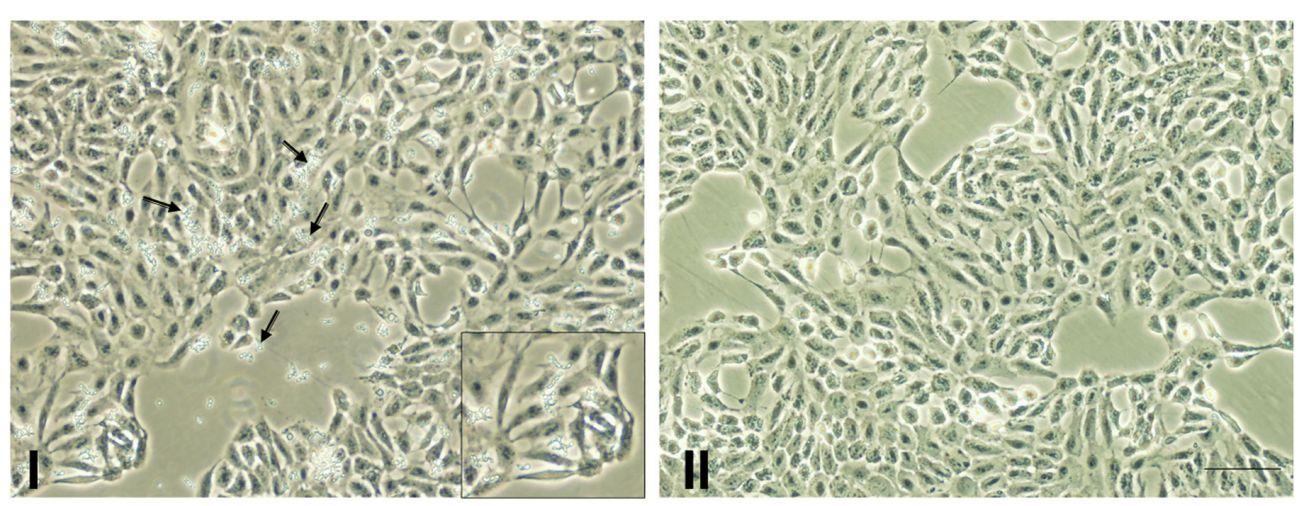

B

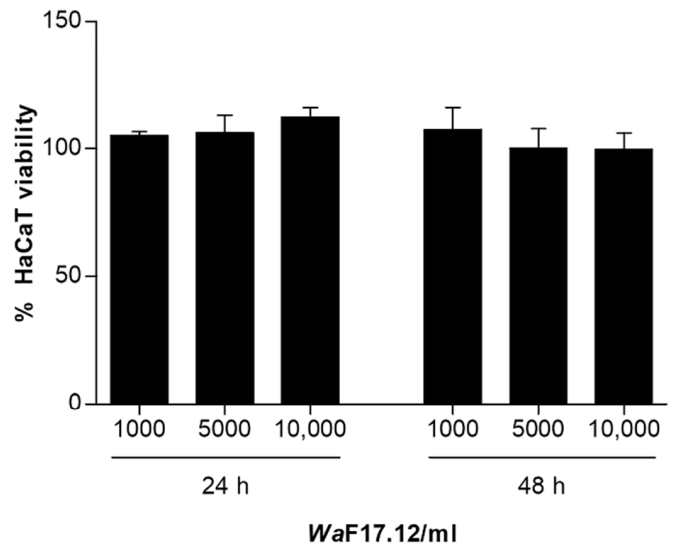

C
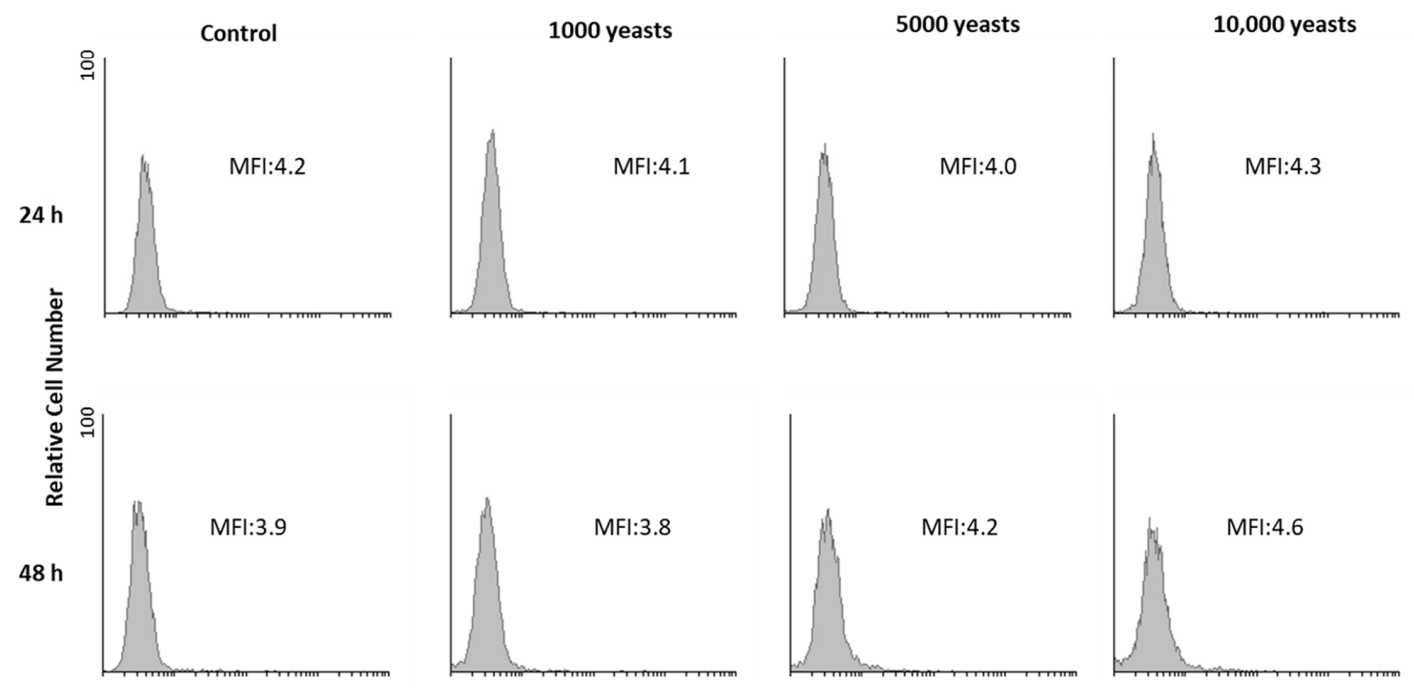

PI

Figure 2. (A) Light microscopy of HaCaT treated with $W a F 17.12(10,000$ yeast cells $/ \mathrm{mL})$ for 48 h: cells before (I) and after (II) washing. The arrows indicate yeasts onto the cell layer. In the magnification, a detail of the yeasts. Bar $=200 \mu \mathrm{m}$. One representative out of three independent experiments is shown. (B) MTT assay was performed in HaCaT cells co-cultured with different concentrations of $W a F 17.12(1000,5000$ and 10,000 yeasts cells $/ \mathrm{mL})$ for $24 \mathrm{~h}$ and $48 \mathrm{~h}$. Data are the mean \pm SD of three separate experiments. HaCaT cells in the medium were used as control (=100\%). (C) PI staining and FACS analysis were performed in HaCaT cells. One representative out of three independent experiments is shown. MFI = mean fluorescence intensity. 
No morphological alterations, no cell detachment and no changes at the differentiation level were found by light microscopy in $\mathrm{HaCaT}$ cells co-cultured with different concentrations of $\mathrm{WaF} 17.12$ (Figure 2A). Interestingly, the yeast does not adhere to the surface of the cell layer and grows suspended in the $\mathrm{HaCaT}$ medium as demonstrated by the yeast removal through washing (Figure 2AI,II).

To deeply investigate the effects induced by WaF17.12 on HaCaT viability, MTT assay, and propidium iodide (PI) staining and FACS analysis were performed. The MTT assay detected no decrease in the number of viable cells in the samples co-cultured with yeasts (non-treated HaCaT cells were used as control $=100 \%$ ) (Figure 2B). The PI assay supported the results by MTT, demonstrating no increment in the cell death rate (MFI = mean fluorescence intensity) (Figure 2C). The overall results showed that treatments with different concentrations of WaF17.12 for $24 \mathrm{~h}$ and $48 \mathrm{~h}$ did not have cytotoxic effects on human keratinocytes and did not affect cell viability.

\subsection{Effect of WaF17.12 on the Proinflammatory Response}

Keratinocytes are able to release several proinflammatory mediators, such as IL-1, IL-6 and $\mathrm{TNF} \alpha$, by participating directly in the immune response [19]. Moreover, in inflamed skin, the STAT3 signaling pathway was found to be activated and overexpressed [20]. Thus, we investigated whether the presence of $\mathrm{WaF} 17.12$ in the HaCaT cell culture was able to stimulate a proinflammatory response. To this purpose, the gene expression of IL-1, IL-6, TNF $\alpha$ and STAT3 was assessed by real-time PCR (Figure 3).

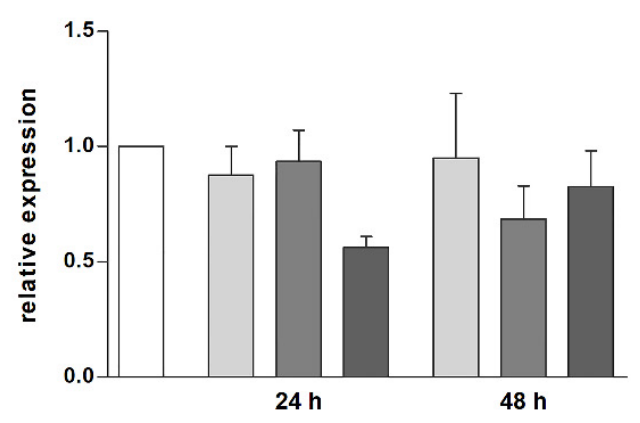

IL-1

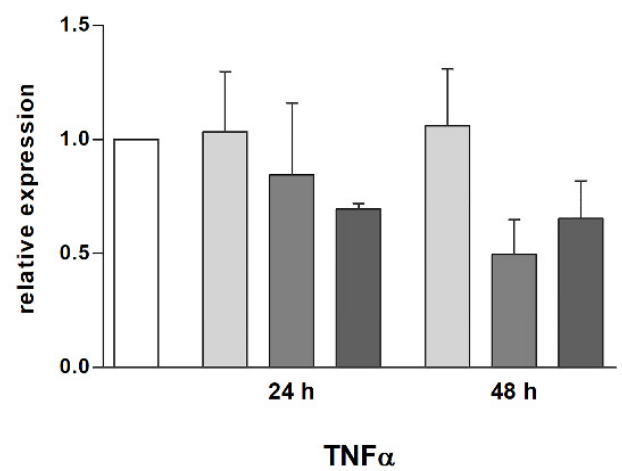

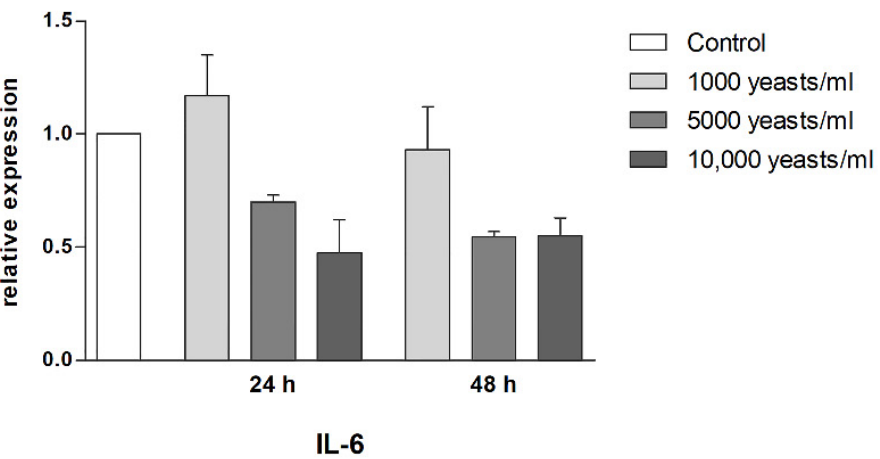

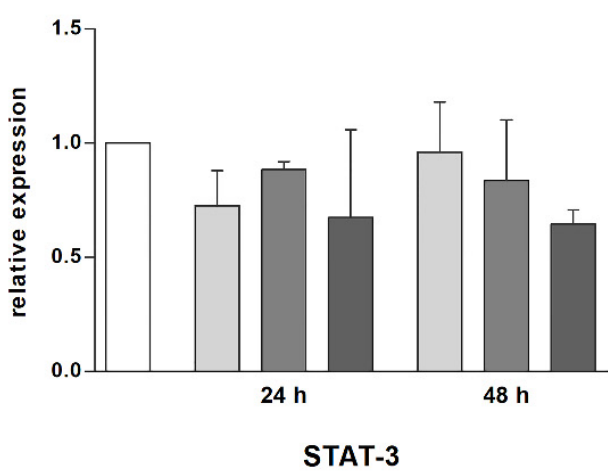

Figure 3. Transcriptional modulation of proinflammatory cytokines (IL-1, IL-6 and TNF $\alpha$ ) and STAT3 genes in HaCaT cells, co-cultured in presence of different concentrations of WaF17.12 for $24 \mathrm{~h}$ and $48 \mathrm{~h}$ or with standard medium (control), evaluated by quantitative RT-PCR. Data are the mean \pm SEM of triplicate samples from two separate experiments and the results are normalized for GAPDH expression used as a housekeeping gene. mRNA levels were expressed as relative fold with respect to $\mathrm{HaCaT}$ cells in medium used as control $(=1)$.

As shown, the incubation for $24 \mathrm{~h}$ or $48 \mathrm{~h}$ of HaCaT cells with different concentrations of $\mathrm{WaF} 17.12$ did not increase gene expression levels in any of the four targets (non-treated 
HaCaT cells cultivated in standard medium were used as control). Different trends in gene expression among yeast amounts were not statistically significant (one-way ANOVA test and the Bonferroni post hoc test).

The expression of the most common inflammatory cytokine TNF $\alpha$ was also assessed at the protein level by Western blot analysis. Our results showed no differences in the expression of the TNF $\alpha$ protein in HaCaT cells co-treated with $W a F 17.12$, compared with control cells (Figure 4).
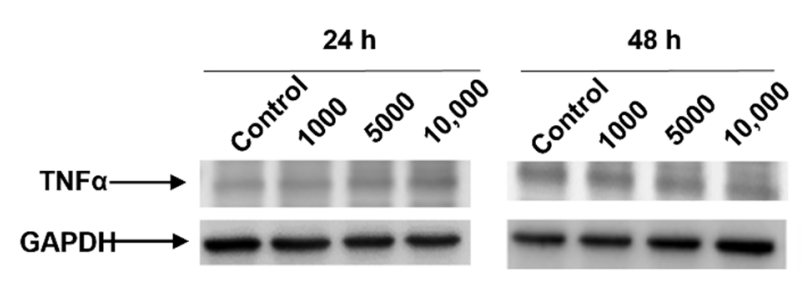

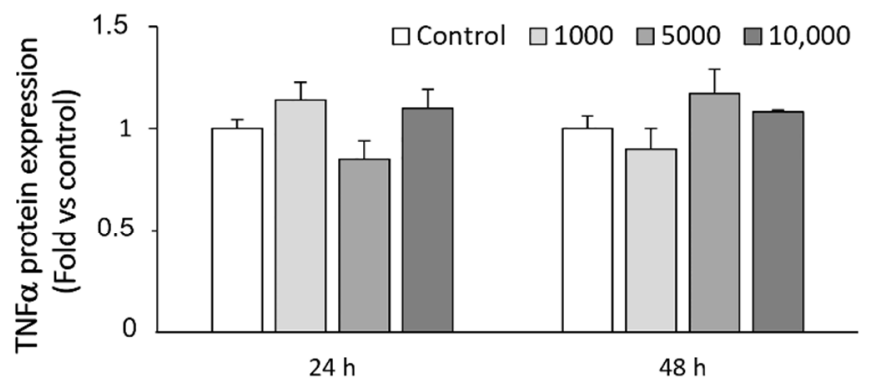

Figure 4. TNF $\alpha$ protein expression was assessed by Western blot analysis in HaCaT cells, co-cultured with different concentrations of $W a F 17.12$ or medium (control) for $24 \mathrm{~h}$ and $48 \mathrm{~h}$. GAPDH was used as loading control. Immunoblots are representative of three separate experiments. Data of densitometric analysis are the mean \pm SD of three separate experiments. Fold represents changes in protein expression with respect to control $(=1)$.

Overall, these results indicated no induction of inflammation in HaCaT cells induced by the presence of $W a \mathrm{~F} 17.12$.

\section{Discussion}

W. anomalus secretes extracellular KTs displaying a wide spectrum of antimicrobial activity against sensitive microorganisms that ensure a dominant role in the competition within the environmental niches. This capability has stimulated its use as a biocontrol agent in the agro-food industry to block the proliferation of undesired microorganisms [21]. Diverse environmental strains are notified to the EFSA as microbiological agents at QPS-1 and have been successfully employed against detrimental microbes, such as Penicillium sp. and Botrytis cinerea, reducing the use of chemical agents [22,23].

A new application of $W$. anomalus has been proposed in the SC of VBDs, after the discovery of strains in mutualistic association with vector insects, such as Anopheles, Aedes and Culex mosquitoes and Phlebotomus perniciosus sand fly [4,24,25]. Diverse studies have been carried out in Anopheles where the killer activity of the symbiotic strain WaF17.12 has been demonstrated to cause structural damage and death of the malaria parasite P. berghei $[8,26]$. Cappelli and collaborators showed that $W a F 17.12$, administered through the diet, is able to stably colonize the female mosquito midgut and gonads, being vertically transmitted to the progeny [16]. Thus, the malaria parasite can be impaired in the midgut by pre-feeding mosquitoes with the killer yeast before the ingestion of an infected blood meal [8]. Since mosquitoes search the sugar for an energy supply soon after the emergence, they would be attracted by odorant feeding stations containing, for example, honey or fruit juice plus $W a F 17.12$. In this view, the dissemination of the killer yeast in newly emerged mosquitoes can be favored through the release of feeding stations near the larval breeding sites (e.g., puddles).

The biological interactions of $W a F 17.12$ with the vector and the parasite guarantee the potential success of this strategy. Nevertheless, a yeast delivery system should be implemented through an inexpensive, environmentally friendly and safe product. In applied view, a lyophilized yeast preparation ready-to-use can be included in the packaging of feeding stations. Several strains of $W$. anomalus used as biocontrol agents in the food industry produce biomass on a large scale [27] and exert stress tolerance after dehydration [15]. On this background, we tested the freeze-drying of WaF17.12, demonstrating 
yeast survival and the killer toxin activity maintenance up to two months of rt storage, and proposing transformation processes that do not require high-cost procedures, such as low temperatures or vacuum systems.

Concerning the $W$. anomalus safety aspect, the evaluation potential toxicity plays a critical role, although the yeast is considered to be non-virulent and is reported rarely as an opportunistic pathogen in immunocompromised patients [28]. On the other hand, a large screening of donors, including different classes of patients and healthy people exposed to mosquito bites, detected a single $W$. anomalus fungemia positive case in an immunocompromised patient [29]. In fact, the biochemical characterization of WaF17.12-KT revealed a glycoproteic structure with an exo- $\beta$-1,3-glucanase activity that binds to specific receptors on the surface of microbes but does not target mammalian cells [30]. To our knowledge, there are a few studies in vitro or in vivo on the toxicity of W. anomalus and KTs $[8,12,13]$. Although yeast KTs appear to be harmless to non-microbial targets, it is important to establish that there are no other yeast toxicity mechanisms. Therefore, in the applied view of SC strategies, we have carried out tests, using live yeast. Our investigations contributed to fill this gap of knowledge, demonstrating that the treatment with WaF17.12 did not affect the cell viability and did not stimulate the production of inflammatory factors in human keratinocytes, which represent the major cell type of the epidermis.

This study suggests the use of the symbiotic killer yeast $W a F 17.12$ as a bioreagent for killing the malaria parasite in vector mosquitoes and limiting the malaria transmission through a sustainable and safe approach.

\section{Conclusions}

Formulation and safety tests performed in the present study showed that WaF17.12 is transformable into a dried product ready to use in the field. The overall data suggest the use of symbiotic killer yeasts as sustainable and safe bioreagents for controlling the malaria spreading.

\section{Materials and Methods}

\subsection{Yeast}

The KT producer strain of $W$. anomalus $W a \mathrm{~F} 17.12$, isolated from An. stephensi mosquitoes [7,16], was tested in this study. The KT non-producer strain WaUM3 was used as a target system, susceptible to $W a F 17.12-K T$, in the antimicrobial activity assay $[16,31]$. For all the experiments of the present study (post-lyophilization assays and tests on keratinocytes), WaF17.12 was cultured at the optimal growth condition for stimulating the $\mathrm{KT}$ production; cells were incubated at $26{ }^{\circ} \mathrm{C}$ and $70 \mathrm{rpm}$ for $36 \mathrm{~h}$ in YPD broth $(20 \mathrm{~g} / \mathrm{L}$ peptone, $20 \mathrm{~g} / \mathrm{L}$ glucose, $10 \mathrm{~g} / \mathrm{L}$ yeast extract), buffered at $4.5 \mathrm{pH}$ with $0.1 \mathrm{M}$ citric acid and $0.2 \mathrm{M} \mathrm{K}_{2} \mathrm{HPO}_{4}[16]$.

\subsection{HaCaT Cells Cultures}

An immortalized human keratinocyte (HaCaT) cell line (Creative Bioarray, Shirley, NY, U.S.A.) was cultured in DMEM (Lonza, Allendale, NJ, U.S.A.) supplemented with 10\% fetal bovine serum (FBS) (EuroClone, Milano, Italy), $2 \mathrm{mM}$ L-glutamine (Lonza, Allendale, NJ, U.S.A.), $100 \mathrm{IU} / \mathrm{mL}$ of penicillin, $100 \mu \mathrm{g}$ of streptomycin (Lonza, Allendale, NJ, U.S.A.) and maintained at $37{ }^{\circ} \mathrm{C}$ with $5 \% \mathrm{CO}_{2}$ and $95 \%$ humidity.

\subsection{Freeze-Drying of WaF17.12}

After cultivation, the WaF17.12 cells were counted with trypan blue in the Neubauer chamber. After two washings with $0.9 \% \mathrm{NaCl}$ solution, six vials containing $10^{7}$ cells $/ \mathrm{mL}$ in fresh medium (YPD pH 4.5) were prepared, and 5\% trehalose was added to preserve the cell viability in the dry state [32]. The samples were immediately frozen $\left(\right.$ at $\left.-80{ }^{\circ} \mathrm{C}\right)$ for $12 \mathrm{~h}$; then, the cultures were transferred to a freeze-dryer (Edwards, Burgess Hill, United Kingdom). Freeze-drying was carried out for $24 \mathrm{~h}$ at $-50{ }^{\circ} \mathrm{C}$ and at a pressure 
of 0.15 mbar [33]. The vials containing lyophilized strains were sealed with Parafilm (Darmstadt, Germany) and stored up to 60 days at rt and protected from light.

\subsection{Growth Rate Assessment and Killer Toxin Activity Assay Post-Lyophilization}

The viable cell number and the antimicrobial activity of WaF17.12-KT were checked in the different yeast preparations $(4,12,18,25,32$ and 60 days post-lyophilization). Per each preparation, $10^{7}$ lyophilized cells $/ \mathrm{mL}$ were rehydrated in sterile water and incubated for culturing, whereas $10^{7}$ fresh (non-lyophilized) cells $/ \mathrm{mL}$ of $W a F 17.12$ were used as control. All yeast samples were cultured at optimal growth conditions for the KT production (see above). After incubation, the WaF17.12 cells were counted by trypan blue in the Neubauer chamber to assess the yeast growth rate after different days of storage. For the killer toxin activity assay, the cultures from the lyophilized samples and the control were centrifuged at $3000 \mathrm{rpm}$ for $5 \mathrm{~min}$, and the supernatant was filtered to eliminate cells. The presence of $\mathrm{WaF} 17.12-\mathrm{KT}$ was detected in all the supernatant by Western blot, using the monoclonal antibody mAbKT4 [16,31]. To test the maintenance of WaF17.12-KT activity after lyophilization, $10^{6}$ cells of $\mathrm{WaUM} 3$ were incubated overnight at $26^{\circ} \mathrm{C}$ and $70 \mathrm{rpm}$ in YPD pH 4.5 diluted with each supernatant (1:1). Since supernatants deriving from previous cultures are to be considered a growth medium that is partially exhausted, the control was performed, using $10^{6}$ cells of WaUM3 incubated in YPD pH 4.5 diluted with a self-supernatant of $36 \mathrm{~h}$ (1:1). After incubation, WaUM3 growth was evaluated by counting with trypan blue in the Neubauer chamber. All samples were assayed in triplicate and the experiment was performed twice. The mean \pm SEM for each group was considered. Statistical analyses were performed using GraphPad Prism 5 software. Multiple comparisons using Mann-Whitney test determined the statistical difference in $W a \mathrm{~F} 17.12$ growth at different time points. The KT activity against $\mathrm{WaUM} 3$ was evaluated in the six treated groups, using the two-way ANOVA and Bonferroni post hoc test. A $p$-value $<0.05$ was considered statistically significant.

\subsection{Treatment of HaCaT Cells with WaF17.12}

The $2 \times 10^{5}$ cells / well were plated in 6-well plates and incubated overnight in supplemented DMEM at $37^{\circ} \mathrm{C}, 5 \% \mathrm{CO}_{2}$ and $95 \%$ of humidity. The cells were treated for $24 \mathrm{~h}$ and $48 \mathrm{~h}$ with different concentrations of $W a F 17.12: 1000,5000$ and 10,000 yeasts cells $/ \mathrm{mL}$. Untreated cells were used as the control. The stimulation was performed in triplicate experiments. The morphology of keratinocytes was analyzed by bright field microscopy, using a fluorescence microscope (Olympus, Milan, Italy).

\subsection{Cell Viability Assays in HaCaT}

Cell death and/or viability induced by different WaF17.12 concentrations (1000, 5000, 10,000 yeasts cells/mL) after $24 \mathrm{~h}$ and $48 \mathrm{~h}$ was evaluated, using MTT (3-(4,5dimethylthiazol-2-yl)-2,5-diphenyltetrazolium bromide) and PI (Sigma-Aldrich, Saint Louis, U.S.A.) assays.

In MTT assay, HaCaT cells $\left(7.5 \times 10^{5}\right.$ cells $\left./ \mathrm{mL}\right)$ were seeded into 96 -well plates and co-cultured with different yeast concentrations or the vehicle (DMEM). Upon treatment, the supernatant was removed, and the cells were washed twice with PBS $1 \times$. MTT $(0.8 \mathrm{mg} / \mathrm{mL})$ was added to the samples and incubated for $3 \mathrm{~h}$. Then, the supernatants were discarded, and $100 \mu \mathrm{L} /$ well DMSO were added to dissolve the formazan crystals. The colored solutions were read by a microtiter plate spectrophotometer (BioTek Instruments, Winooski, VT, U.S.A.). Six replicates were used for each treatment. The experiments were repeated three times.

For the PI assay, HaCaT cells were incubated with $20 \mu \mathrm{g} / \mathrm{mL}$ of PI in $1 \times$ PBS, for $30 \mathrm{~min}$ at $20^{\circ} \mathrm{C}$. PI penetrates cells with altered membranes intercalating with the broken DNA, a typical process of cell necrosis. Samples were analyzed by a FACScan cytofluorimeter, using the CellQuest software. The experiments were repeated three times. 


\subsection{Gene Expression Analysis of Proinflammatory Mediators}

The relative expression of four genes involved in the pro-inflammatory response (IL-1, IL-6, TNF $\alpha$ and STAT-3) was evaluated. HaCaT cells were treated with $\mathrm{WaF} 17.12$ as previously described. Total RNA was extracted with RNAzol ${ }^{\circledR}$ RT following the manufacturer instructions (Sigma-Aldrich, St. Louis, MI, U.S.A.). Total RNA (1 $\mu \mathrm{g})$ was subjected to reverse transcription, using PrimeScript ${ }^{\mathrm{TM}}$ RT reagent Kit (Takara, Kusatsu, Giappone), and qRT-PCR was performed by using CFX96 Touch Real-Time PCR Detection System (BioRad, Hercules, CA, U.S.A.). The reaction mixture contained $1 \times$ PCR Brilliant Multiplex QPCR Master Mix (Agilent, Stratagene), PrimePCR Probe Assays with FAM or HEX fluorophore (BioRad, Hercules, CA, U.S.A.) used, according to company datasheet. PCR parameters were $10 \mathrm{~min}$ at $95^{\circ} \mathrm{C}$ followed by 40 cycles of $95^{\circ} \mathrm{C}$ for $30 \mathrm{~s}$ and $55^{\circ} \mathrm{C}$ for $30 \mathrm{~s}$ and $72{ }^{\circ} \mathrm{C}$ $30 \mathrm{~s}$. All samples were assayed in triplicate. The relative amount of target mRNA of IL-1, IL-6, TNF $\alpha$, STAT3 and GAPDH (housekeeping gene) was calculated by the 2- $\Delta \Delta \mathrm{Ct}$ method. Statistical analysis was performed using the Bio-Rad CFX Manager Software and the GraphPad software (http:/ / www.graphpad.com). For each group, mean values and the standard error (SEM) from two independent experiments were calculated. One-way ANOVA test and the Bonferroni post hoc test were used to assess the statistical differences between gene expressions.

\subsection{Western Blot Analysis of TNF $\alpha$}

$\mathrm{HaCaT}$ cells untreated or treated with different WaF7.12 concentrations $(1000,5000$ and 10,000 yeasts cells $/ \mathrm{mL}$ ) for $24 \mathrm{~h}$ and $48 \mathrm{~h}$ were suspended in a lysis buffer containing protease inhibitor cocktail (Sigma Aldrich, St. Louis, MO, U.S.A.). Lysates were separated on $14 \%$ SDS polyacrylamide gel in a Mini-PROTEAN Tetra Cell system (BioRad, Hercules, CA, U.S.A.) and transferred onto nitrocellulose membranes (EuroClone, Milano, Italy), using Mini Trans-Blot Turbo RTA system (BioRad). Blots were incubated with a blocking solution containing $3 \%$ bovine serum albumin (BSA) in PBS $1 \times$ and $0.1 \%$ Tween 20 for $1 \mathrm{~h}$ at rt. Membranes were incubated overnight at $4{ }^{\circ} \mathrm{C}$ in anti-human TNF $\alpha$ primary antibody $(\mathrm{Ab})$ diluted 1:1000 in PBS tween + BSA 3\% (Enzo Life Science, Farmingdale, New York, U.S.A.) followed by incubation for $1 \mathrm{~h}$ at $\mathrm{rt}$ with HRP-conjugated anti-mouse secondary $\mathrm{Ab}$. As a loading control, membranes were incubated with anti-GAPDH 1:1000 PBS-tween in milk $5 \%$ for $1 \mathrm{~h}$ at $\mathrm{rt}$ followed by the appropriate HRP-conjugated secondary $\mathrm{Ab}$, according to the specific datasheet. Detection was performed, using the LiteAblot ${ }^{\circledR}$ PLUS kit (EuroClone, Milano, Italy). As positive control for the TNF $\alpha$ expression, $\mathrm{HaCaT}$ cells were treated with $1 \mu \mathrm{M}$ etoposide for $24 \mathrm{~h}$ [17].

Author Contributions: Conceptualization, I.R. and A.C.; methodology, A.C. and C.A.; formal analysis, G.F.; investigation, F.M.; data curation, A.C.; writing-original draft preparation, A.C. and C.A.; writing-review and editing, I.R.; supervision, I.R.; funding acquisition, I.R. All authors have read and agreed to the published version of the manuscript.

Funding: The work was supported by the European Union Horizon 2020 under Grant Agreement No. 842429 to IR.

Institutional Review Board Statement: Not applicable.

Informed Consent Statement: Not applicable.

Conflicts of Interest: The authors declare no conflict of interest. The funders had no role in the design of the study; in the collection, analyses, or interpretation of data; in the writing of the manuscript, or in the decision to publish the results. 


\section{References}

1. Walker, G.M. Pichia anomala: Cell physiology and biotechnology relative to other yeasts. Antonie Van Leeuwenhoek 2011, 99, 25-34. [CrossRef] [PubMed]

2. Allende, A.; Bolton, D.; Chemaly, M.; Davies, R.; Salvador, P.; Escamez, F.; Girones, R.; Herman, L.; Koutsoumanis, K.; Lindqvist, R.; et al. Update of the list of QPS-recommended biological agents intentionally added to food or feed as notified to EFSA 4: Suitability of taxonomic units notified to EFSA until March 2016. EFSA J. 2017, 15, 4663. [CrossRef]

3. Cappelli, A.; Favia, G.; Ricci, I. Wickerhamomyces anomalus in Mosquitoes: A Promising Yeast-Based Tool for the "Symbiotic Control" of Mosquito-Borne Diseases. Front. Microbiol. 2021, 11, 621605. [CrossRef] [PubMed]

4. Martin, E.; Bongiorno, G.; Giovati, L.; Montagna, M.; Crotti, E.; Damiani, C.; Gradoni, L.; Polonelli, L.; Ricci, I.; Favia, G.; et al. Isolation of a Wickerhamomyces anomalus yeast strain from the sandfly Phlebotomus perniciosus, displaying the killer phenotype. Med. Vet. Entomol. 2016, 30, 101-106. [CrossRef] [PubMed]

5. Liu, N.N. Insecticide Resistance in Mosquitoes: Impact, Mechanisms, and Research Directions. Annu. Rev. Entomol. 2015, 60, 537-559. [CrossRef] [PubMed]

6. Benelli, G.; Jeffries, C.L.; Walker, T. Biological Control of Mosquito Vectors: Past, Present, and Future. Insects 2016, 7, 52. [CrossRef] [PubMed]

7. Ricci, I.; Damiani, C.; Scuppa, P.; Mosca, M.; Crotti, E.; Rossi, P.; Rizzi, A.; Capone, A.; Gonella, E.; Ballarini, P.; et al. The yeast Wickerhamomyces anomalus (Pichia anomala) inhabits the midgut and reproductive system of the Asian malaria vector Anopheles stephensi. Environ. Microbiol. 2011, 13, 911-921. [CrossRef] [PubMed]

8. Cappelli, A.; Valzano, M.; Cecarini, V.; Bozic, J.; Rossi, P.; Mensah, P.; Amantini, C.; Favia, G.; Ricci, I. Killer yeasts exert anti-plasmodial activities against the malaria parasite Plasmodium berghei in the vector mosquito Anopheles stephensi and in mice. Parasites Vectors 2019, 12, 329. [CrossRef]

9. Stefanini, I. Yeast-insect associations: It takes guts. Yeast 2018, 35, 315-330. [CrossRef] [PubMed]

10. Madden, A.A.; Epps, M.J.; Fukami, T.; Irwin, R.E.; Sheppard, J.; Sorger, D.M.; Dunn, R.R. The ecology of insect-yeast relationships and its relevance to human industry. Proc. Biol. Sci. 2018, 285, 20172733. [CrossRef]

11. Passoth, V.; Olstorpe, M.; Schnurer, J. Past, present and future research directions with Pichia anomala. Antonie Van Leeuwenhoek 2011, 99, 121-125. [CrossRef] [PubMed]

12. Zhang, Q.R.; Zhao, L.N.; Li, Z.B.; Li, C.; Li, B.; Gu, X.Y.; Zhang, X.Y.; Zhang, H.Y. Screening and identification of an antagonistic yeast controlling postharvest blue mold decay of pears and the possible mechanisms involved. Biol. Control 2019, 133, 26-33. [CrossRef]

13. Junges, D.S.B.; Delabeneta, M.F.; Rosseto, L.R.B.; Nascimento, B.L.; Paris, A.P.; Persel, C.; Loth, E.A.; Simao, R.C.G.; Menolli, R.A.; Paula, C.R.; et al. Antibiotic Activity of Wickerhamomyces anomalus Mycocins on Multidrug-Resistant Acinetobacter baumannii. Microb. Ecol. 2020, 80, 278-285. [CrossRef] [PubMed]

14. Jarque, S.; Bittner, M.; Hilscherova, K. Freeze-drying as suitable method to achieve ready-to-use yeast biosensors for androgenic and estrogenic compounds. Chemosphere 2016, 148, 204-210. [CrossRef] [PubMed]

15. Stefanello, R.F.; Nabeshima, E.H.; Iamanaka, B.T.; Ludwig, A.; Fries, L.L.M.; Bernardi, A.O.; Copetti, M.V. Survival and stability of Lactobacillus fermentum and Wickerhamomyces anomalus strains upon lyophilisation with different cryoprotectant agents. Food Res. Int. 2019, 115, 90-94. [CrossRef] [PubMed]

16. Cappelli, A.; Ulissi, U.; Valzano, M.; Damiani, C.; Epis, S.; Gabrielli, M.G.; Conti, S.; Polonelli, L.; Bandi, C.; Favia, G.; et al. A Wickerhamomyces anomalus killer strain in the malaria vector Anopheles stephensi. PLoS ONE 2014, 9, e95988. [CrossRef]

17. Rossi, P.; Cappelli, A.; Marinelli, O.; Valzano, M.; Pavoni, L.; Bonacucina, G.; Petrelli, R.; Pompei, P.; Mazzara, E.; Ricci, I.; et al. Mosquitocidal and Anti-Inflammatory Properties of The Essential Oils Obtained from Monoecious, Male, and Female Inflorescences of Hemp. Molecules 2020, 25, 3451. [CrossRef]

18. Colombo, I.; Sangiovanni, E.; Maggio, R.; Mattozzi, C.; Zava, S.; Corbett, Y.; Fumagalli, M.; Carlino, C.; Corsetto, P.A.; Scaccabarozzi, D.; et al. HaCaT Cells as a Reliable In Vitro Differentiation Model to Dissect the Inflammatory/Repair Response of Human Keratinocytes. Mediat. Inflamm. 2017, 2017, 7435621. [CrossRef] [PubMed]

19. Sangiovanni, E.; Fumagalli, M.; Pacchetti, B.; Piazza, S.; Magnavacca, A.; Khalilpour, S.; Melzi, G.; Martinelli, G.; Dell’Agli, M. Cannabis sativa L. extract and cannabidiol inhibit in vitro mediators of skin inflammation and wound injury. Phytother. Res. 2019, 33, 2083-2093. [CrossRef]

20. Sano, S.; Chan, K.S.; Carbajal, S.; Clifford, J.; Peavey, M.; Kiguchi, K.; Itami, S.; Nickoloff, B.J.; DiGiovanni, J. Stat3 links activated keratinocytes and immunocytes required for development of psoriasis in a novel transgenic mouse model. Nat. Med. 2005, 11, 43-49. [CrossRef]

21. Mannazzu, I.; Domizio, P.; Carboni, G.; Zara, S.; Zara, G.; Comitini, F.; Budroni, M.; Ciani, M. Yeast killer toxins: From ecological significance to application. Crit. Rev. Biotechnol. 2019, 39, 603-617. [CrossRef]

22. Parafati, L.; Vitale, A.; Restuccia, C.; Cirvilleri, G. The effect of locust bean gum (LBG)-based edible coatings carrying biocontrol yeasts against Penicillium digitatum and Penicillium italicum causal agents of postharvest decay of mandarin fruit. Food Microbiol. 2016, 58, 87-94. [CrossRef]

23. Oro, L.; Feliziani, E.; Ciani, M.; Romanazzi, G.; Comitini, F. Volatile organic compounds from Wickerhamomyces anomalus, Metschnikowia pulcherrima and Saccharomyces cerevisiae inhibit growth of decay causing fungi and control postharvest diseases of strawberries. Int. J. Food Microbiol. 2018, 265, 18-22. [CrossRef] 
24. Ricci, I.; Mosca, M.; Valzano, M.; Damiani, C.; Scuppa, P.; Rossi, P.; Crotti, E.; Cappelli, A.; Ulissi, U.; Capone, A.; et al. Different mosquito species host Wickerhamomyces anomalus (Pichia anomala): Perspectives on vector-borne diseases symbiotic control. Antonie Van Leeuwenhoek 2011, 99, 43-50. [CrossRef]

25. Steyn, A.; Roets, F.; Botha, A. Yeasts Associated with Culex pipiens and Culex theileri Mosquito Larvae and the Effect of Selected Yeast Strains on the Ontogeny of Culex pipiens. Microb. Ecol. 2016, 71, 747-760. [CrossRef]

26. Valzano, M.; Cecarini, V.; Cappelli, A.; Capone, A.; Bozic, J.; Cuccioloni, M.; Epis, S.; Petrelli, D.; Angeletti, M.; Eleuteri, A.M.; et al. A yeast strain associated to Anopheles mosquitoes produces a toxin able to kill malaria parasites. Malar. J. 2016, 15, 1-9. [CrossRef] [PubMed]

27. Melin, P.; Schnurer, J.; Hakansson, S. Formulation and stabilisation of the biocontrol yeast Pichia anomala. Antonie Van Leeuwenhoek 2011, 99, 107-112. [CrossRef] [PubMed]

28. Dutra, V.R.; Silva, L.F.; Oliveira, A.N.M.; Beirigo, E.F.; Arthur, V.M.; da Silva, R.B.; Ferreira, T.B.; Andrade-Silva, L.; Silva, M.V.; Fonseca, F.M.; et al. Fatal Case of Fungemia by Wickerhamomyces anomalus in a Pediatric Patient Diagnosed in a Teaching Hospital from Brazil. J. Fungi 2020, 6, 147. [CrossRef] [PubMed]

29. Epis, S.; Capone, A.; Martin, E.; Paolucci, M.; Bazzocchi, C.; Valzano, M.; Bozic, J.; Novati, S.; Favia, G.; Ricci, I. A rapid qPCR method to investigate the circulation of the yeast Wickerhamomyces anomalus in humans. New Microbiol. 2015, 38, 577-581. [PubMed]

30. Cecarini, V.; Cuccioloni, M.; Bonfili, L.; Ricciutelli, M.; Valzano, M.; Cappelli, A.; Amantini, C.; Favia, G.; Eleuteri, A.M.; Angeletti, M.; et al. Identification of a Killer Toxin from Wickerhamomyces anomalus with beta-Glucanase Activity. Toxins 2019, 11, 568. [CrossRef] [PubMed]

31. Polonelli, L.; Seguy, N.; Conti, S.; Gerloni, M.; Bertolotti, D.; Cantelli, C.; Magliani, W.; Cailliez, J.C. Monoclonal yeast killer toxin-like candidacidal anti-idiotypic antibodies. Clin. Diagn. Lab. Immunol. 1997, 4, 142-146. [CrossRef] [PubMed]

32. Melin, P.; Hakansson, S.; Schnurer, J. Optimisation and comparison of liquid and dry formulations of the biocontrol yeast Pichia anomala J121. Appl. Microbiol. Biotechnol. 2007, 73, 1008-1016. [CrossRef] [PubMed]

33. Nahr, F.K.; Mokarram, R.R.; Hejazi, M.A.; Ghanbarzadeh, B.; Khiyabani, M.S.; Benis, K.Z. Optimization of the nanocellulose based cryoprotective medium to enhance the viability of freeze dried Lactobacillus plantarum using response surface methodology. Lwt-Food Sci. Technol. 2015, 64, 326-332. [CrossRef] 